\title{
DERECHO PENAL ECONÓMICO VENEZOLANO: BASES CONSTITUCIONALES
}

Venezuelan economic criminal law: constitutional bases

Carlos Simón Bello Rengifo* UNIVERSIDAD CENTRAL DE VENEZUELA CARACAS, VENEZUELA

* Universidad Central de Venezuela, Caracas, Venezuela, Facultad de Ciencias Jurídicas y Políticas Instituto de Ciencias Penales de Caracas. Correo electrónico: carlos.simon.bello@gmail.com.

Artículo recibido el 27 de marzo de 2018 y aceptado para publicación el 13 de julio de 2018. 
Resumen: El Derecho Penal se inserta en el marco de derechos y garantías constitucionalmente establecidos, de allí la importancia que para el Derecho Penal Económico guardan las normas relativas a la actividad económica, que diseñan la Constitución Económica. La Carta Magna venezolana, por la inestabilidad del sistema normativo y, por los dominios de control económico del Estado, suprime el intercambio libre del mercado, y corresponde a un modelo de Estado de Bienestar, tendencialmente totalitario, por lo que no legitima bienes jurídicos penales económicos.

Palabras Clave: Estado de Derecho, Estado de Bienestar, Constitución Económica, Estado Constitucional, Sistema socio-económico.

ABSTRACT: The Criminal Law, including also, the economic criminal law, is inserted in the Constitution, in its framework of rights and guarantees, and that's why, the importance of the rules of the Economic Constitution. The model of Welfare State in Venezuela is tendentiously totalitarian because the normative system of the Constitutionis unstable and as well the domains of economic 'control suppress the rules of free market, and deprives the economic criminal legal right.

KEY WORDS: Rule of Law, Welfare State, Economic Constitution, Constitutional State, Socioeconomic System. 


\section{INTRODUCCIÓN}

La Constitución debe contener el orden de los valores imperantes en la sociedad y manifestar sus decisiones político-jurídicas esenciales y entonces "señala los rumbos, objetivos, y los mecanismos para desarrollar las tareas estatales, cuyo cometido central es la dignificación del ser huma$n o^{\prime \prime}$. Esto lleva consigo el reconocimiento, respeto, defensa y amparo de los derechos y garantías que le son consustanciales, y, en consecuencia, que el individuo goce de las condiciones adecuadas para desarrollar su plan existencial dentro de un marco jurídico que no lo mutile, ni como individuo ni como ser social.

Entre los derechos consustanciales, también condición del desarrollo y realización del plan existencial del individuo en sociedad, está la libertad, en todas sus esferas de actividad y pensamiento.

Por tanto, la Constitución debe ser el marco jurídico de primer orden que reconoce, ampara y protege los derechos consustanciales del individuo, $y$ sus preceptos deben proclamar los principios y valores fundamentales de la sociedad organizada, y regular la interacción humana en sociedad con preceptos generales y valorativos cuya interpretación, en su devenir histórico-social, aliente un ordenamiento coherente, con mensajes normativos claros de consecuencias previsibles. El concepto de Estado de Derecho se corresponde con este objetivo, al regular el ejercicio de la fuerza y el poder según las restricciones que imponen los valores jurídicos excluyentes del ejercicio de la fuerza absoluta en la vida de la polis.

El reconocimiento, defensa y amparo de los derechos consustanciales del individuo, fundamentos de su dignidad, también corresponde al Derecho Penal Económico, cuya función es definir y sancionar comportamientos económicos injustos, es decir, aquellos que lesionen o pongan en peligro, por medios intolerables, bienes jurídico- económicos, especialmente importantes para el individuo, la sociedad y sus instituciones, frente a los cuales no existan otros medios razonables de defensa y resguardo.

1 Gómez (2008) p. 41. 
Por ello, importa comparar las disposiciones constitucionales que declaren, promuevan, prohíban o restrinjan la intervención del Estado en la actividad económica, expresión del ejercicio de la libertad, con el círculo de derechos y garantías individuales protectoras ante el ejercicio del poder que, de no limitarse, puede transgredirlos en detrimento de la dignidad humana.

Esta comparación demostrará, en mi opinión, que la Constitución de la República Bolivariana de Venezuela (en adelante CV-99), contiene normas excluyentes entre sí, y que el predominio de muchas de ellas, implica que es autoritaria y tendencialmente totalitaria, lo que implica que dicho círculo es irrespetado, y que tampoco aporta materialidad suficiente para la reacción penal, según el enfoque liberal. La extensión de la comparación a la Constitución derogada de 1961 fortalecerá la demostración de la hipótesis, que impone, primeramente, delinear la relación que existe la Constitución y el Derecho Penal Económico.

\section{RELACIÓN ENTRE LA CONSTITUCIÓN Y EL DERECHO PENAL ECONÓMICO}

Entre las normas constitucionales reguladoras de los poderes del Estado y las que reconocen los derechos individuales, hay una conexión sinérgica, o una total o parcial inestabilidad, lo que incide en la homogeneidad y coherencia de los órdenes legales que conforman e interactúan en el sistema jurídico, pues, aun admitiendo que por su generación y evolución, es propio que haya desequilibrios, incluso en la Constitución; sin embargo, si alcanzan un nivel máximo, entonces ocurre el predominio, generalmente precario y opresivo, de unos elementos sobre otros, ${ }^{2}$ para restablecer el equilibrio extraviado.

2 El siguiente párrafo del discurso de Enrique Tejera, con ocasión de la clase magistral “La Constitución somos todos" en la apertura de los cursos de posgrado de la Facultad de Ciencias Jurídicas y Políticas de la Universidad Católica Andrés Bello (Venezuela), en marzo de 1999, guarda relación con lo dicho: "La salud de las naciones, la de su constitución, es tan variable y sorpresiva como la constitución de los seres humanos y consiste en la comparación con la situación aparente y más o menos conocida de otros cuerpos considerados "sanos". La constitución social o política también puede ser débil o robusta, sanguínea o linfática, estable o cambiante. Nuestros sistemas están como en lucha constante y mientras uno de ellos no domine a los demás, desequilibrándonos, no hay motivo aparente de preocupación, en las personas jurídicas como en las personas naturales". 
La coherencia y la homogeneidad están entre los atributos más abstractos y propios del sistema jurídico, al menos en el sentido aproximativo propio de la teleología del quehacer doctrinario y legislativo, sin logros irremplazables, pues como creación humana es susceptible de cambios, no siempre queridos ni previsibles, que propician incertidumbre y tensiones. Además, el desarrollo y evolución de la sociedad y su orden ético, político y jurídico, son fuentes de relativa y permanente tensión, pero cuando se fractura el continuum evolutivo surgen las crisis y una relación distinta: un orden diferente que sustituye al precedente.

El alivio y salidas a las tensiones se debe procurar, primeramente, con una estructura constitucional propia de un sistema jurídico constitucional, que legitime el subsistema jurídico penal, u orden jurídico penal al que pertenece el penal económico; sin embargo, estos objetivos se frustran si la estructura constitucional padece de desequilibrios irreconciliables, o si los desequilibrios se salvan con el dominio de un espacio autoritario o tendencialmente totalitario, sobre el de los derechos humanos.

Un elemento relevante del orden jurídico penal es el bien jurídico, que puede ser también considerado vínculo con el orden constitucional, por lo cual es punto de referencia obligado para la interpretación de los tipos, pues permite arribar al fin de la norma y a la ratio de la incriminación. ${ }^{3}$

La funcionalidad del bien jurídico actúa, asimismo, en la articulación de los poderes del Estado, incluyendo los económicos, con los derechos individuales. Además, dota de materialidad al injusto, cuya lesión o peligro, se conecta con lo social, ${ }^{4}$ donde adquiere horizonte y sentido el orden jurídico punitivo. ${ }^{5}$

3 Arteaga (2012) p. 208.

4 La doctrina vincula los delitos de lesión o peligro según el grado de afectado al bien jurídico. Así, aquellos injustos en los cuales el bien jurídico sufre un menoscabo material o ideal, se consideran de lesión; mientras que son de peligro aquellos cuya realización requiere una conducta estadísticamente peligrosa o un efectivo peligro de lesión. Modolell (2015) pp. 67 y 68. En sentido Roxin (2014) p. 91 citando a JeSCHECK y MILA (2014) p. 288.

5 En el injusto se halla el objeto de valoración y, por tanto, el sustrato de la conducta imputable, como fuente de su realización voluntaria y su potencialidad de ataque al bien jurídico tutelado por el tipo. Este sustrato es valorado en dos pasos. En la tipicidad, es decir, su inclusión en la definición típica de la conducta y, en segundo lugar, en la antijuridicidad del hecho "que consiste en que la conducta lesiva seleccionada conceptualmente por el legislador como punible no esté cubierta por una causa de justificación, ya que esto determina que la conducta ya no 
La génesis del bien jurídico es capítulo abierto en la dogmática; sin embargo, no puede negarse que, para su fundamentación, explicación y comprensión, la Constitución es relevante porque ella representa los valores nucleares de la sociedad. Por tanto, el legislador, el juez y el intérprete están vinculados, aunque distintamente, a los valores que la Carta reconoce y proclama, explícita o implícitamente.

Asimismo, de este horizonte normativo, los agentes jurídicos deben acercarse, por intermedio del caso concreto, a la realidad social y política, ${ }^{6}$ valiéndose del recurso de la lógica, pero sin desprenderse del respeto sustancial a las garantías constitucionales. En conclusión: lógica, topos y marco constitucional.

Vale insistir en que el tejido constitucional es decisivo para entender cuáles son los bienes jurídicos más importantes para la organización social, pues provee parámetros críticos a las decisiones legislativas y es guía, tanto para la creación como para la interpretación y aplicación de las normas penales, al reconocer valores, principios y garantías que configuran el modelo constitucional del Estado, y activan su programa. Es por eso que la armadura constitucional del bien jurídico, constituye un mecanismo de defensa y resguardo de los derechos humanos, ante los eventuales abusos del poder. Si vale el símil, genera una funcionalidad inmunológica, ante ataques que pueden surgir, incluso desde el mismo sistema jurídico, cuando es desnaturalizado como simple instrumento del poder.

El tejido constitucional incluye la Constitución Económica que, en una primera aproximación, se puede definir como el conjunto de normas reguladoras de la relación del agente económico con el poder.

García-Pelayo la define como las normas básicas destinadas a proporcionar el marco jurídico fundamental para la estructura y funcionamiento de la actividad económica o, dicho de otro modo, para el orden y el proceso económico, aunque, agrega, no garantiza un determinado orden económico, salvo las constituciones socialistas. ${ }^{7}$

encuadre dentro de las prohibidas por el tipo bajo amenaza de pena". FERNÁNDEZ (2012) p. 45.

BALCARCE (2014) pp.106 y 107. El autor se refiere específicamente a la dogmática y el positivismo crítico; sin embargo, su planteamiento también es válido respecto al legislador y el juez, con las diferencias del caso.

7 García-Pelayo (1991) p. 2857. Aclara que su origen se remonta a W. Eucken (Cuestiones funda- 
En su opinión, son tres las materias que la integran: régimen de propiedad, formas de relación entre los actores económicos y distribución de competencias; pero, las distintas exigencias políticas y sociales que van surgiendo en el desarrollo histórico de cada nación conducen a una pluralidad semántica que pueden generar "efectos perversos", es decir, ni queridos ni deseados. ${ }^{8}$

El esclarecimiento de los principios de la Constitución Económica se puede establecer considerando, primero, el modelo de Estado, así como del tipo de relación, cercana o distante, conceptual y operativa, entre el sistema socioeconómico, que la Constitución Económica comprende, y la defensa y resguardo de los derechos humanos y los bienes jurídicos, lo que exige una tarea crítica de los valores ético-políticos del sistema jurídico penal (jurídico penal económico, en este caso), incluso cuando hay neutralidad.

Esta tarea comienza a partir delos derechos y deberes individuales y su relación con el Derecho Penal, porque ellos revelan la concepción constitucional del hombre y su correlativa dignidad, inseparable de la libertad y de su consecuencial responsabilidad, pues la dignidad es anclaje de la primera y presupuesto de la segunda.

En síntesis, la Constitución puede abrigar preceptos incompatibles que conduzcan a una máxima inestabilidad que, en definitiva, se decide a favor de algunos que predominan sobre otros en aras de la estabilidad y coherencia del mundo normativo. Por otra parte, el concepto de bien jurídico, fundamental en el orden jurídico penal, vincula este último con la Constitución, pues ella es referente de los principios y valores del sistema jurídico globalmente considerado, y en cuanto el Derecho

mentales de la economía política, 1939. Madrid, 1947), inspirado en la definición de constitución política de Carl Schmitt, y agrega que en Alemania el Tribunal Constitucional decidió que la Ley Fundamental de Bonn es neutral y dejó abiertas distintas posibilidades al legislador. En la doctrina venezolana más reciente, se destaca que los derechos económicos conjuntamente con el Estado Social son "elementos claves" de la Constitución Económica. PeÑA (2014) pp. 225 y 226.

8 García-Pelayo (1991) pp. 2858 y 2871. La admisión de la posibilidad de "efectos perversos", indica, por argumento en contrario que sí puede haber principios, valores, objetivos y planteamientos propios de una determinada opción económica en constituciones democráticas, es decir, las que no representan la ideología socialista soviética, por lo puede no haber neutralidad en la constitución económica de países democráticos. Ahora, que pueda haber un sistema económico no democrático en una Constitución democrática, no equivale a decir que puedan coexistir en el terreno de la historia. 
Penal Económico, el nexo se establece con la Constitución Económica, cuya determinación está en función del modelo de Estado, su relación con el sistema socio-económico, la defensa y resguardo de los derechos humanos y de los bienes jurídicos, a los que se accede mediante juicios valorativos de carácter ético-político.

Antes de abordar los principios y valores claves de la Constitución Económica y su relevancia jurídica-penal, es necesario detenerse brevemente en la concepción, en la CV-99 de la persona humana, núcleo de los derechos fundamentales.

\section{PERSONA HUMANA EN LA CV-99}

La concepción de la persona humana en la CV-99, se puede extraer de la configuración del Estado, contenida en sus disposiciones iniciales.

El artículo 2 establece que la nación venezolana se organiza como un Estado democrático y social de Derecho y de Justicia, asentado sobre unos determinados valores superiores que, a su vez, actúan como fines del cuerpo social (vida, libertad, justicia, igualdad, solidaridad, democracia, responsabilidad social, preeminencia de los derechos humanos, ética y pluralismo político). Estos fines se asocian a otros que versan sobre el individuo como tal: defensa y desarrollo de la persona y el respeto a su dignidad (Artículo 3, encabezamiento).

El desarrollo de la persona humana es posible, en tanto se respete su dignidad y el ejercicio de su libertad, sin los cuales, no cabe responsabilidad. Luego dignidad y libertad constituyen un binomio inseparable de la responsabilidad, y en su conjunto conforman el trípode que sustenta un sistema jurídico-liberal.

La dignidad humana puede ser definida como un atributo del ser humano, de carácter integral, ineludible y general que "implica el necesario reconocimiento de que todos los seres humanos, iguales entre sí, son titulares, ontológicamente hablando, de una igual dignidad y que esta dignidad se integra con todos los derechos humanos, los civiles, los políticos, 
las economías (sic), sociales y culturales". ${ }^{9}$ Funcionalmente considerada es un tope al Derecho punitivo, límite cualitativo respecto a los hechos y modalidad de sanción, y cuantitativo en cuanto las penas.

Por su parte, la libertad es el espacio inviolable por el Derecho Penal, en la medida en que la acción u omisión no vulneren el espacio de otros; en tanto que la responsabilidad es exigible, según la dignidad, a quien vulnera la libertad del otro. Dignidad, libertad y responsabilidad se apoyan a su vez en la voluntad del asociado. Como dice Fernández Carrasquilla: "el Derecho solo puede prohibir comportamientos voluntarios del hombre (conductas) y sus resultados causales previsibles y evitables". ${ }^{\prime 0}$ Por tanto, esa capacidad de control, previsión y evitabilidad, como materia de prohibición, solo es posible para quien goza de autonomía de voluntad.

La CV-99 es prolífica en la enunciación de derechos colectivos o sociales, e igualmente concede preeminencia a los derechos humanos, como valor y fin del Estado, amén de la cláusula abierta de su artículo 22, según el cual su enunciación no niega aquellos que sean inherentes a la persona, aunque no se mencionen expresamente. También vale recordar que el artículo 23 eius dem otorga jerarquía constitucional y preeminente a los Tratados, Pactos y Convenciones sobre derechos humanos.

Este marco normativo, inobjetable de principio, coexiste con otras normas de tendencia opuesta. En primer lugar, hay que citar el artículo 20, según el cual: "Toda persona tiene derecho al libre desenvolvimiento de su personalidad, sin más limitaciones que las que derivan del derecho de los demás y del orden público y social".

La limitación a la libertad según el "orden público y social", definidos por el Estado, sin necesaria ofensa al derecho y libertad de otro, resultan fortalecidos, especialmente en el ámbito económico, por lo cual queda privado de contenido efectivo el derecho al libre desenvolvimiento de la personalidad, condición del ejercicio de la libertad.

Lo expuesto puede hacer pensar que el ámbito punitivo debe limitarse a las ofensas individuales, lo que no es admisible en el Derecho

9 Gros (2005) p. 271.

10 Fernández Carrasquilla (2012) p. 87. 
contemporáneo, pero sí expresa que es un mínimo inviolable de intervención penal legítima. Lo que está más allá de ese límite será materia a tratar posteriormente, con ocasión de los derechos colectivos, que denomino socio-institucionales.

El conjunto de derechos y garantías en su triple dimensión de dignidad, libertad y responsabilidad, en su faz económica, se integran en la Constitución Económica, como sistema socioeconómico. ${ }^{11}$

El análisis del sistema socioeconómico demostrará el autoritarismo y tendencia totalitaria de la CV-99, pero no se puede prescindir, como paso previo, de algunas consideraciones sobre las diferencias básicas que, en el orden económico, existen con la derogada de 1961, entre las cuales, resalta la ausencia del concepto de sistema en esta última, comparación que culmina con algunas consideraciones básicas sobre el concepto de sistema y su configuración socioeconómica en la CV-99.

\section{CONSTITUCIÓN DE 1961}

Promulgada a raíz de la caída de la dictadura militar de Marcos Pérez Jiménez, recoge el espíritu de la de 1947, fruto de la llamada Revolución de Octubre, primer texto constitucional que acogió normas intervencionistas en la economía, además de ampliar los derechos sociales que, en el campo laboral, declaró la de 1936.

La Constitución de 1961 prosiguió en el reconocimiento de la justicia social como base del régimen económico de la República, e igualmente pauta la intervención del Estado como promotor de la economía, ${ }^{12}$ y reconoce

11 La CV-99 emplea cuarenta veces la voz "sistema", no siempre con el mismo significado y sentido, pero no puede negarse la importancia que la misma tiene en el discurso normativo, y en ocasiones se emplea para organizar sectores institucionales (penitenciario, justicia, por ejemplo), o para revelar la organización misma de la sociedad: sistema socioeconómico.

12 Artículo 95: "El régimen económico de la República se fundamentará en principios de justicia social que aseguren a todos una existencia digna y provechosa para la colectividad. El Estado promoverá el desarrollo económico y la diversificación de la producción, con el fin de crear nuevas fuentes de riquezas, aumentar el nivel de ingresos de la población y fortalecer la soberanía económica del país". 
la libertad económica, artículo 96, "sin más limitaciones que las previstas en esta Constitución y las que establezcan las leyes por razones de seguridad, de sanidad u otras de interés social".

La presencia del Estado interventor en el artículo $98,{ }^{13}$ no le asigna a la planificación el rol fundamental que ordena la CV-99, ni prevé delitos e ilícitos económicos, pues la prohibición de la usura, la elevación indebida de precios y de las maniobras abusivas es para proteger la libertad económica, finalidad ausente en la CV-99.

Un examen más detallado de la CV-99 demostrará que la diferencia entre ambas Constituciones más que de grado, es conceptual. Este examen comenzará con el concepto de "sistema", esencialen su discurso y aplicación.

\section{SISTEMA SOCIO-ECONÓMICO}

Sin pretender una exhaustiva lista de definiciones del concepto "sistema", que desbordaría los límites y objetivos de este trabajo, ${ }^{14}$ véase al menos alguna representativa.

"Un sistema es una estructura transformada entidad homogénea y cerrada por efecto de la intervención de coordinación, entendiendo por esta última la actividad estructurante que determina y mantiene los principios de la coherencia en el momento de la definición del sistema".15

Esta definición destaca el carácter formal del sistema, porque como tal no existe una cosa que sea un sistema, aunque cualquier cosa puede servista y analizada como un sistema, de allí sus ventajas epistemológicas y heurísticas, y entre ellas, según el fundador de la teoría general de sistemas (Von Bertalanffy), la isomorfía entre los mundos natural y social, que permite un

13 "El Estado protegerá la iniciativa privada, sin perjuicio de la facultad de dictar medidas para planificar, racionalizar y fomentar la producción y regular la circulación, distribución y consumo de la riqueza, a fin de impulsar el desarrollo económico de país".

14 La mayoría resalta, según el tipo de sistema, conceptos como elemento, ambiente, relación, estabilidad y finalidad.

15 Voltes (1978) p. 29. 
papel similar al de la lógica aristotélica en las ciencias de la Antigüedad;:16 y aunque ese objetivo no está plenamente logrado, puede ser un método de variable utilidad y rendimiento, incluso en el mundo jurídico. ${ }^{17}$

Como método aplicado al Derecho Constitucional relaciona las normas jurídicas con las estructuras políticas, según ha sido adoptado por un sector de la doctrina constitucional venezolana, valiéndose deciertas definiciones básicas: objetivos, entendidos como un todo y como las formas de actuación en su integridad; ambiente, como la relación con otros sistemas (jurídico, político, social) y las restricciones que impone; recursos, como los componentes e interacciones entre los elementos y, por último, administración. ${ }^{18}$

Esta propuesta, no del todo desarrollada, es metodológicamente útil para determinar las bases constitucionales del Derecho Penal económico venezolano, para lo cual también hay que describir la configuración constitucional de la actividad económica según el concepto de "sistema socioeconómico", modelado básicamente por el artículo 299, ${ }^{19}$ cuyos objetivos se clasifican así:

Primarios: "asegurar el desarrollo humano integral y una existencia digna y provechosa para la colectividad." Secundarios: "generar fuentes de trabajo, alto valor agregado nacional, elevar el nivel de vida de la población y fortalecer la soberanía económica del país". El instrumental: planificación estratégica, democrática, participativa y de consulta abierta. El nivel superior que rige respecto a todos los demás: "lograr una justa distribución de la riqueza".

16 Ramírez (1999) p.21.

17 El término "sistema" goza de abolengo jurídico, pero su sentido es otro en la teoría general de sistemas.

18 Álvarez (2012) p. 15. En lo sucesivo, me referiré básicamente a los objetivos.

19 Título VI Del sistema socioeconómico. Capítulo I. Del régimen socioeconómico y la función del Estado en la economía. Artículo 299: "El régimen socioeconómico de la República Bolivariana de Venezuela se fundamenta en los principios de justicia social, democracia, eficiencia, libre competencia, protección del ambiente, productividad y solidaridad, a los fines de asegurar el desarrollo humano integral y una existencia digna y provechosa para la colectividad. El Estado conjuntamente con la iniciativa privada promoverá el desarrollo armónico de la economía nacional con el fin de generar fuentes de trabajo, alto valor agregado nacional, elevar el nivel de vida de la población y fortalecer la soberanía económica del país, garantizando la seguridad jurídica, solidez, dinamismo, sustentabilidad, permanencia y equidad del crecimiento de la economía, para lograr una justa distribución de la riqueza mediante una planificación estratégica democrática participativa y de consulta abierta". 
Sus componentes son varios. Axiológicos: principios de justicia social, democracia y solidaridad. Otros son de carácter variado: técnico-económico: eficiencia y productividad; económico: libre competencia; ecológico: protección del ambiente; y obligacionales: promoción del desarrollo armónico de la economía nacional, garantizando la seguridad jurídica, solidez, dinamismo, sustentabilidad, permanencia y equidad del crecimiento de la economía.

Normativamente considerado, el sistema socioeconómico comprende valores y principios proclamados en el Preámbulo y en el Título I (Principios Fundamentales), que son, además, pauta hermenéutica para la totalidad del sistema, ${ }^{20}$ y para el sub-sistema de derechos y garantías. Estos valores, principios, derechos y garantías son significativos para la determinación del bien jurídico, especialmente si abarca los derechos económicos del Capítulo VII, ${ }^{21}$ trascendentes al sistema punitivo; mas, puede ocurrir que la tensión entre esos principios y valores con otras normas constitucionales relevantes para el poder penal, fracture la conexión. ${ }^{22}$

Otra configuración del sistema socioeconómico constitucional, es según zonas económicas de control y de dominio del Estado correspondientes a las actividades que pueden desarrollar particulares y el Estado, separadamente, o solo el Estado, o bien las reguladas. Las zonas de control significan distintas actividades económicas realizables por agentes económicos no estatales -sujetas a limitaciones constitucionales, que pueden llegar hasta suprimir la acción privada e individual-, mientras que las zonas de

20 En este caso, desde un punto de vista más general, el sistema socioeconómico es no más que un subsistema del sistema jurídico constitucional; sin embargo, he mantenido la voz "sistema" basado en la letra constitucional.

21 Del mismo cabe reproducir el artículo 112, pues contiene la declaración más general de principios y derechos económicos: "Todas las personas pueden dedicarse libremente a la actividad económica de su preferencia, sin más limitaciones que las previstas en esta Constitución y las que establezcan las leyes, por razones de desarrollo humano, seguridad, sanidad, protección al ambiente u otras de interés social. El Estado promoverá la iniciativa privada, garantizando la creación y justa distribución de la riqueza, así como la producción de bienes y servicios que satisfagan las necesidades de la población, la libertad de trabajo, empresa, comercio, industria, sin perjuicio de su facultad para dictar medidas para planificar, racionalizar y regular la economía e impulsar el desarrollo integral del país."

22 También el sistema socioeconómico puede ser abordado según diversos elementos: de protección (bienes jurídicos); de interpretación (valores y principios) y de organización (normas de ordenación y jerarquización). 
dominio son la recaudación fiscal, la política monetaria y la coordinación macroeconómica, y en las cuales los agentes económicos privados tienen un rol fundamentalmente pasivo, término inexacto, pero con potencia intuitiva para revelar una idea básica de relativa claridad.

La ampliación de la comprensión del sistema socioeconómico, conduce a su marco general, el modelo de Estado.

\section{MODELOS DE ESTADO}

\section{Preliminar}

Según el artículo 2 de la CV-99, el Estado venezolano es "democrático y social, de Derecho y de Justicia". Es decir, sus propiedades bimembres son: democrático y social, en primer lugar, y de Derecho y de Justicia, a continuación. ${ }^{23}$

Esta fórmula reelabora el concepto de Estado de Derecho, cuyo análisis conceptual es lo que sigue.

\section{Estado de Derecho}

Enseña Peña ${ }^{24}$ que, actualmente, el Estado de Derecho se define, en lenguaje formal, desde la premisa del sometimiento del Estado y sus poderes al Derecho. Este último, en el sentido del positivismo jurídico,

23 Tal declaración no existía ni en la Constitución del 61, ni en su antecedente inspirador, la efímera Constitución del 47 que, según Brewer Carías, adoptó el modelo de Estado democrático y social de Derecho. BreWER (2008) p 99. Este modelo de Estado ha sostenido la doctrina nacional relevante, es acorde con la libertad económica y un Estado ordenador y conformador de la realidad económica a fin de realizar la justicia social, que equivale, según sostiene, a la "economía social de mercado" de los países europeos.

24 PeÑA (2008) pp. 295 y 296. Agrega PeÑa (2008) p. 297, que esta óptica fue la esgrimida por los regímenes totalitarios del siglo XX, cuando sostenían que sus respectivos Estados eran de Derecho porque se regían por leyes, argumento que hoy en día es igualmente invocado por los gobiernos de Cuba y Corea del Norte. 
no se concibe más allá de la Ley, por lo cual excluye todo derecho que no esté legalmente reconocido. ${ }^{25}$

Durante su larga evolución, el Estado de Derecho, desde la Revolución Francesa, ha registrado una progresiva limitación de los poderes del Estado para someterlo a la racionalidad jurídica que impone como límites los derechos individuales (libertad, igualdad, propiedad), y exige la garantía de su ejercicio (debido proceso, habeas corpus). Posteriormente, gracias a luchas políticas, se fueron agregando la separación de poderes y la independencia de los jueces. ${ }^{26}$

La inclusión y reconocimiento de estos derechos no evitó la tragedia del totalitarismo, lo que obligó a una nueva concepción del Estado de Derecho que incorpora el elemento axiológico, como núcleo de su contenido, colocando los principios al servicio de su efectiva ejecución. Como dice Santamaría: "(el) Estado de Derecho debe ser concebido como un principio material de ordenación de la actividad estatal, la cual ha de dirigirse a la consecución de valores determinados, el más importante de los cuales es el de la garantía y protección de la libertad personal y política. Forma y contenido del Estado de Derecho se unen, pues, en una síntesis inescindible". ${ }^{27}$

Decisiva, en esta evolución,es la Ley Fundamental de Bonn, ${ }^{28}$ que añade a la concepción formal, la prohibición de violar el contenido esencial de los derechos, ${ }^{29}$ o sea, principios y valores: "Solo planteado constitucionalmente así, se erigirán en parámetros indispensables, distintos a los formales, principios y valores como la democracia, la dignidad humana, la seguridad jurídica, la igualdad, la vida, el pluralismo político, la justicia, $y$, en general, todos los contenidos de los derechos fundamentales. De tal manera que, en ese contexto, no bastará identificar la existencia de los elementos que configuran formalmente al Estado de Derecho, antes mencionados: principio de legalidad de la Administración Pública, prin-

25 Peña (2008) pp. 295 y 296.

26 PeÑA (2008) p. 298. Un elemento que destaca Peña, entre los que fueron incorporados al concepto, es el principio de legalidad administrativa, que es el sometimiento de la Administración al Derecho, a la norma jurídica, a fin de proteger al ciudadano ante sus posibles abusos.

27 Peña (2008) p. 299.

28 Artículo 20: "La República Federal de Alemania es un Estado federal democrático y social".

29 Artículo 19, numeral $2^{\circ}$ : "En ningún caso un derecho fundamental podrá ser afectado en su contenido esencial". 
cipio de separación de poderes, de independencia del Poder Judicial y garantía patrimonial, pues será necesario examinar el contenido y orientación de la actividad estatal, para poder emitir opinión sobre la existencia de un verdadero Estado de Derecho, es decir, en sentido material". ${ }^{30}$

El enriquecimiento material del Estado de Derecho, con miras a una mejor y mayor realización de sus fines y razones, según sus defensores, genera la fórmula Estado Social de Derecho, parcialmente acogido en la CV-99.

\section{Estado Social de Derecho y Estado de Bienestar}

La fórmula "Estado Social de Derecho" ha predominado desde la II Guerra Mundial, pero no son escasas las diferencias legislativas y decisiones político-económicas entre Estados con la misma cobertura conceptual, ${ }^{31}$ por lo que se puede pensar que "Estado Social de Derecho" es una especie de banda conceptual y operativa con distintas manifestaciones, que, muchas veces, topa con una "zona gris", la del Estado de Bienestar, con el cual tiene diferencias cuantitativas o de intensidad. Por ello, es improbable fijar una forma jurídica precisa del Estado Social de Derecho diferenciada del Estado de Bienestar, que más que una configuración jurídica del Estado, es una conformación política económica, al igual que la economía de mercado, resultantes de determinadas decisiones políticas antes que de preceptos constitucionales expresos que, por lo general, están en una zona de cierta neutralidad que sin desconocer derechos fundamentales, permiten un margen de acción al gobierno para una orientación, alejada o cercana, al modelo ideal de economía de mercado. ${ }^{32}$

30 Peña (2008) p. 300.

31 La Constitución de Portugal, por ejemplo, no auspicia un orden económico de mercado, sino de transición al socialismo, y sin embargo, su sistema económico no es estatista. Su artículo 2 expresa: La República portuguesa es un Estado democrático y de transición al socialismo. La República portuguesa es un Estado democrático, basado en la soberanía popular, en el respeto y la garantía de los derechos y libertades fundamentales y en el pluralismo de expresión y de organización política democráticas, y tiene por objetivo asegurar la transición hacia el socialismo mediante la creación de condiciones para el ejercicio democrático del poder por las clases trabajadoras.También, hay naciones constituidas como Estados de Derecho que no propician una economía de mercado, pero han transitado de Estado de Bienestar hacia economías de mercado, como ha ocurrido en los últimos tiempos en algunos países de América Latina.

32 Las diferencias fácticas entre el Estado de Bienestar y la economía de mercado no siempre 
Según Sotelo, el telón de fondo del Estado Social es el capitalismo, cuya modernización trajo cambios políticos, económicos y sociales que generaron tres revoluciones: científico-tecnológica, política y socioeconómica que no originaron un único modelo, pues sus manifestaciones ocurrieron en contextos muy distintos unos de otros, ${ }^{33}$ y aunque se tienda a confundir con el Estado de Bienestar, opina, es necesario hacer una distinción en dos modelos: el social-liberal y el socialdemócrata. ${ }^{34}$

En el primero, hay interés por los más débiles en momentos de crisis temporal o definitiva, y apela a la "solidaridad" como la obligación del Estado de hacerse cargo de los que no se pueden cuidar por sí mismos, sin modificación sustancial del orden capitalista. En cambio, el modelo socialdemócrata invoca la justicia social y hace de la política de igualación social "un instrumento imprescindible para construir una sociedad más justa", considerando que la desigualdad arrebata la libertad a los más pobres, por lo que eleva la satisfacción de las necesidades de los más débiles a derechos. La diferencia básica entre ambos la establece el ancho trecho entre la "justicia social" y la "solidaridad". 35

El concepto de "justicia social" proveniente de la doctrina social de la Iglesia, especialmente de las encíclicas Rerum Novarum y Cuadragésimo Anno, de los papas León XIII y Pío XI, respectivamente, e incluso de Centesimus Annus de San Juan Pablo II, fue acogida por el pensamiento social demócrata, como un esquema que se acerca al socialismo en su reclamo de igualdad y también, al liberalismo en su defensa de la propiedad privada, pero limitándola.

Hoy tiende a ser sustituida por una nueva síntesis humanista propuesta por Benedicto XVI, que propone un horizonte antropológico, ético y cultural que reanime la vida de las instituciones y la vida política en general, y recupere categorías, como la donación, que permitan realizar proyectos morales en estos tiempos: "En el escenario político, la lógica del don se hace presente en varias dinámicas democráticas que la hacen operativa y productiva para

son excluyentes entre sí, aunque partan de supuestos teóricos distintos, lo que demuestra la importancia de las decisiones políticas, fruto de criterios ambiguos, cuando no opuestos, y de oportunidad.

33 Sotelo (2010) p. 118.

34 En definitiva, es el conflicto sobre el predominio entre libertad e igualdad.

35 Sotelo (2010) pp. 286 y ss. 
una re-moralización de la actividad política". ${ }^{36}$ El valor de la democracia y la corrección moral de la acción política emergen como centros de atención, en vez del rescate de la pobreza de los menos favorecidos que no son olvidados, solo se transforma el modo de acercamiento y redención.

Otra clasificación del Estado Social es la que distingue entre "democrático" y "no democrático". En el primero, hay un conjunto de instituciones "complementarias" de economías corporativas en expansión, "evolutivas" que no rompen con las instituciones económicas del capitalismo y promueve la negociación entre capital y trabajo, con el arbitrio del Estado. En cambio, el no democrático atiende al conjunto de instituciones "compensatorias" de los costes del crecimiento económico capitalista, subordinadas a los intereses económicos y sociales dominantes, dictadas desde la esfera superior bajo la presión de los conflictos sociales. ${ }^{37}$

En síntesis, el Estado Social de Derecho es un fenómeno complejo que conjuga, como resultado de su evolución, aspectos políticos, jurídicos, sociales, económicos, entrelazados entre sí. ${ }^{38}$

La fórmula de la CV-99 del Estado Social de Derecho se alteró con un enunciado más complejo: "Estado democrático y social de Derecho y de Justicia", ${ }^{9}$ inclusión que altera el modelo de Estado Social de Derecho, ergo la Constitución Económica. De allí, la importancia de detenerse en su componente "justicia".

\section{El componente Justicia}

La Exposición de Motivos incluye distintas evocaciones al referirse al artículo 2: "Se define la organización jurídico-política que adopta la Nación

36 Moratalla (2014) pp. 89 y 90.

37 Moratalla (2014) p. 29.

38 SOTELO (2010) p.117.

39 Artículo 2: "Venezuela se constituye en un Estado democrático y social de Derecho y de Justicia, que propugna como valores superiores de su ordenamiento jurídico y de su actuación, la vida, la libertad, la justicia, la igualdad, la solidaridad, la democracia, la responsabilidad social y en general, la preeminencia de los derechos humanos, la ética y el pluralismo político." Enunciado similar al artículo $1^{\circ}, 1$, de la Constitución española: "España se constituye en un Estado social y democrático de Derecho, que propugna como valores superiores de su ordenamiento jurídico la libertad, la justicia, la igualdad y el pluralismo político". 
venezolana como un Estado democrático y social de Derecho y de Justicia. De acuerdo con esto, el Estado propugna el bienestar de los venezolanos, creando las condiciones necesarias para su desarrollo social y espiritual, y procurando la igualdad de oportunidades para que todos los ciudadanos puedan desarrollar libremente su personalidad, dirigir su destino, disfrutar los derechos humanos y buscar la felicidad" (el destacado es propio).

Parece obvio que el ejercicio de la libertad no se separe de sus condiciones espirituales y materiales, por lo que, prima facie, no parece irracional sostener que el artículo $2^{\circ}$ de la CV-99 no contraría el pensamiento liberal y que, por tanto, no impide la opción económica del mercado; pero, no hay que caer en precipitaciones.

La cláusula "democrático y social" no se debe desligar de su segunda parte: "de Derecho y de Justicia", ya que forman una unidad semántica, ni tampoco del conjunto de disposiciones que auspician profusamente la intervención estatal, ${ }^{40}$ lo que invita a dilucidar cómo se relaciona el factor "justicia" con la organización jurídica del Estado, y sus consecuencias económicas.

Antes, una breve crónica sobre la inclusión del término.

Según Peña, nació con una propuesta del constituyente Brewer Carías, cuando se refirió a un escrito célebre en su época (1864), del autor Bahr, evocado por Schmitt (1934), que abogaba por someter los actos del Estado a los tribunales de justicia, lo que no es más que acentuar la potestad controladora de los tribunales sobre los actos del Estado, sin marcada diferencia con el Estado de Derecho, salvo que se considere un perfeccionamiento de su fórmula definitoria. Equivale, sostiene Peña, a la tutela judicial. Considera que esa propuesta fue puramente tangencial, sin relación con el valor o ideal de justicia, pero por su carga emocional atrajo a todos los miembros de la Asamblea Constituyente, sin ir acompañada de ningún debate para analizar su sentido y alcance. ${ }^{41}$

Es decir, fue una calificación por emoción, no por razón. O sea, populismo jurídico.

40 Verbos como propugnar", "crear" y "procurar" abundan en las normas constitucionales del sistema socioeconómico.

41 Peña (2008) pp. 372 y 373. 
En este contexto, un párrafo de Zagrebelsky, citado por Peña, revela los peligros en ciernes del apelativo "de justicia" aplicado a la organización estatal: Vendrían a ser los entes colectivos, como expresión de la sociedad, los guardianes del Estado de Justicia, más que los particulares, y ello justifica que dichos entes puedan ejercer acciones tendentes al reconocimiento y declaración de derechos no enunciados. ${ }^{42}$

En pocas palabras, la calificación "de justicia" en la estructura semántica, jurídica e ideológica de la definición del Estado de Derecho no añade más seguridad a la defensa y protección de la dignidad humana basada en el respeto de sus derechos esenciales.

En el Derecho Comparado ${ }^{43}$ tampoco hay parangón que dilucide el alcance de la fórmula constitucional venezolana, pues ni siquiera su génesis histórica aporta algo nuevo o distinto a la obligación del Estado de Derecho de proporcionar tutela jurídica al ciudadano ante los actos del poder, salvo que se entienda la "justicia" como "justicia social", concepto nada irrelevante para el orden socioeconómico, normativa y políticamente considerado.

Para continuar explorando el significado y efectos que pueda tener el elemento "justicia" en la formulación del Estado, hay que remitirse a otros dispositivos.

Según el artículo 30, el Estado tiene entre sus "fines esenciales" la "construcción de una sociedad justa", ${ }^{4}$ cuyo alcance no se precisa; pero, considerándolos otros fines esenciales del Estado y la declaración de sus valores superiores, ${ }^{45}$ que exhibe tanto ascendencia liberal, como linaje democrático y social, lo que de suyo no es extraordinario, ${ }^{46}$ se tiene que

42 PeÑA (2008) p. 373.

43 En la Constitución española, de reconocida influencia en algunas disposiciones de la CV-99, la justicia aparece, en segundo lugar, entre sus valores superiores, luego de la libertad, primer lugar, seguida de la igualdad, tercer término, y el pluralismo político, por último.

44 Este concepto es un semillero de teorías de filosofía política. Al respecto, Philippe Van Parijs hace un recuento de las mismas. Vid. VAN PARIJS (1992).

45 La vida, la libertad, la justicia, la igualdad, la solidaridad, la democracia, la responsabilidad social y en general, la preeminencia de los derechos humanos, la ética y el pluralismo político (Artículo $2^{\circ}$ ).

46 Así lo ha reconocido el Tribunal Constitucional español: "la constitución es un marco de coincidencias suficientemente amplio como para que dentro de él quepan todas las opciones políticas de muy diferente signo". En el mismo sentido, Rubio Llorente: "los preceptos materiales 
la CV-99 funciona como salvoconducto al totalitarismo por la inserción de elementos que dan prevalencia a la concepción no democrática del Estado de Bienestar, ${ }^{47}$ y por el dirigismo que la insufla en perjuicio de los principios liberales y del Estado de Derecho. Su máxima tensión causa un desequilibrio que culmina en la prevalencia de unos elementos sobre otros.

En razón de la enorme cantidad de tareas interventoras del Estado Social previstas por la CV-99, no parece desatinado sostener que, en principio, se conforma como un Estado de Bienestar que no depende exclusivamente de decisiones de gobierno, como puede ocurrir en marcos constitucionales menos explícitos. ${ }^{48}$

Sin embargo, el Estado de Bienestar puede transformarse, desde sus fundamentos, en un Estado autoritario y tendencialmente totalitario, por actos de gobierno, en ocasiones legitimados por un orden constitucional debilitado en cuanto la defensa de la dignidad humana y sus derechos consustanciales, como ocurre en la CV-99.

En definitiva, el adjetivo "de Justicia" a la fórmula constitucional no es un añadido sin consecuencias. Véase ahora por qué.

de la Constitución, a diferencia de los preceptos legales, no pueden disciplinar conductas o habilitar para concretas actuaciones de ejecución, sino garantizar el respeto a determinados valores, o asegurar a los ciudadanos unos derechos que han de ser necesariamente definidos en términos que hagan posibles diversas políticas, esto es, diversas interpretaciones". Cfr. MÁrQuez (2014) p. 101.

47 Se entiende que Estado Social de Derecho no es sinónimo de Estado de Bienestar, pese a su innegable cercanía, y que este último fortalece los mecanismos interventores bajo la promesa de realizar los derechos humanos.

48 El Estado de Bienestar resulta del acompañamiento de ingente cantidad de derechos colectivos, la debilidad de los deberes y la limitación de derechos individuales. La crisis a que ha estado sujeto en los últimos años puede tomarse como demostración que no necesariamente un Estado Social de Derecho es un Estado de Bienestar, pero ello no es materia a desarrollar en esta colaboración. 
El Estado, según la CV-99, promete satisfacer como derechos un enorme conjunto de expectativas sociales, ${ }^{49}$ lo que lo lleva a asumir la hercúlea tarea de:

- Construir la sociedad (justa y amante de la paz).

Lo justo depende, claro está, de lo que el Estado considere que es justo. Si la sociedad sin la tutela interventora del Estado no es justa, entonces éste tiene que controlar para que sea justa, pues sin la acción del Estado no lo es, dicho sea grata argüendi.

- Planificar, racionalizar y regular la economía.

Estos cometidos suponen un plan según determinados objetivos, pues se parte de que, sin su intervención, la actividad económica no es ni justa, ni racional, o al menos, no lo es "del todo".

- Garantizar la justa distribución de la riqueza.

La premisa de esta función es que la distribución de la riqueza sin la intervención del Estado no es justa ni racional. Solo el Estado está provisto de la racionalidad y del sentido de lo que es justo. Solo el Estado es enteramente justo y racional.

Consiguientemente, lo "justo", según la CV-99, está condicionado por parámetros de racionalidad -planificación, construcción, regulación-, irrealizables si quedan bajo el solo arbitrio de la mera voluntad o deseos individuales.

El discurso de la CV-99 recurre a la emotividad ancestral de la nacionalidad, ${ }^{50}$ con exhortaciones que permitirían "justificar" cualquier acto de

49 La asunción de prestaciones concebidas como derechos exigibles, no obstante la imposibilidad manifiesta de muchos de ellos de ser susceptibles de un reclamo efectivo que se traduzca en su ejecución y aplicación por el obligado, el Estado, y no solo por razones meramente políticas, sino también por razones materiales, tendría por sí solo peso suficiente para concluir que el Estado de Justicia no es en nada distinto al Estado de Bienestar, incluso anclado en el Estado de Derecho; pero, hay elementos para pensar lo contrario.

50 "Ejemplo histórico" de Simón Bolívar, "heroísmo y sacrificio" de los "antepasados aborígenes y de los precursores y forjadores" de la patria "libre y soberana", con reiterado y equivocado 
poder que soslaye la racionalidad democrática, pues la emotividad es ingrediente favorable al totalitarismo, por su mayor afinidad con el espíritu mágico que con la racionalidad. El primero es su fuente primigenia, la segunda es instrumental. ${ }^{51}$

A las tareas estatales anteriores, se agrega la de defender y amparar el valor moral de la "solidaridad" - uno de los principios del sistema socioeconómico-y la "responsabilidad social", cuya práctica conlleva la imposición de mandatos a determinados modos de relación de los individuos con el colectivo, abstracción esta última que termina siendo definida y ejercida por quienes ejercen el poder político que, unido al militar, el económico y el institucional, puede imponer a los ciudadanos obligaciones generales y específicas en nombre de la solidaridad y de la responsabilidad social, que aunque justifiquen algunos deberes públicos - los impositivos, por ejemplo -, se hipertrofian cuando se convierten en postulados generales que abarquen cualquier ámbito de la vida individual.

En resumen, la fórmula constitucional del Estado venezolano dilata el Estado Social de Derecho en términos de Estado de Bienestar que, a su vez, deriva en un diseño de Estado autoritario y tendencialmente totalitario, como se ve a continuación.

\section{5.- El Estado de Bienestar autoritario y tendencialmente totalitario}

Si se entiende el autoritarismo como la condición de un Ejecutivo con poderes sin control o débilmente controlado, y hay normas constitucionales que lo demuestran, puede afirmarse que la CV-99 concibe el Estado en términos de autoritarismo. Varias razones sostienen esta conclusión.

El Ejecutivo ostenta facultades normativas sin expresa limitación de su contenido y alcance (artículo 236, numeral $8^{\circ}$ ), por vía de ley habilitante, sin sujeción a control posterior por el Legislativo, a diferencia de la de

"olvido" del aporte colonial en la hechura de las bases republicanas.

51 La vinculación con fuerzas "mágicas" ancladas en el imaginario y sentir colectivos no es nada extraño en muchos fenómenos políticos que cubren el espectro del colectivismo, desde el totalitarismo más extremo del nazismo y el comunismo, hasta los autoritarismos latinoamericanos, sin excluir el populismo tendencialmente totalitario que marca el inicio del siglo en Venezuela. 
1961, que solamente regía para "medidas extraordinarias en materia económica o financiera cuando así lo requiera el interés público" (Artículo 190, numeral $8^{\circ}$ ). Esta habilitación sin control material y limitado formal -ley habilitante-, ha hecho posible que el Ejecutivo dicte mayor número de decretos leyes, incluso penales, que la Asamblea Nacional.

El concepto de seguridad de la Nación, si bien basado en algunos principios irrecusables, también invoca otros como el de justicia y solidaridad, cuyo entramado alberga peligros para la libertad y los derechos humanos, al abarcar fines tan extensos como la "satisfacción progresiva de las necesidades individuales y colectivas de los venezolanos y venezolanas", y con bases que comprometen el universo de la actividad económica: "desarrollo sustentable y productivo de plena cobertura para la comunidad nacional" (artículo 326), que, sometida a la planificación estratégica (artículo 299), hace posible que la seguridad de la Nación comprenda cualquier cosa, incluso por vía de ley habilitante, para lo que es suficiente que el partido de gobierno cuente con mayoría parlamentaria, fenómeno muy común en las democracias, incluso sólidas, mucho más en países de amplia tradición presidencialista.

Leyes derivadas del marco constitucional dan lugar, por ejemplo, a que la actividad científica, tecnológica e investigación sea declarada de "interés público y interés general"52 e integrada al Sistema Nacional de Ciencia, Tecnología e Innovación dirigido por un plan del Ejecutivo que fija los objetivos en esas actividades, en el sector público, y asimismo en el privado y las universidades. ${ }^{53}$

Algo similar ocurre con la actividad bancaria, que según la Ley de Instituciones del Sector Bancario, es un servicio público ${ }^{54}$ lo que más allá del debate conceptual, abre las puertas de una injerencia que exceda los mecanismos de autorización, sin necesidad de una nacionalización expresa.

Un Estado habilitado para intervenir profundamente en la actividad económica y con amplios poderes del Ejecutivo, escasamente controlados, es un Estado autoritario, al menos en mi óptica liberal; pero, además, puede

52 Artículo 2 de la Ley Orgánica de Ciencia, Tecnología e Innovación.

53 Artículos 10, 11 y 12.

54 Ley de Instituciones del Sector Bancario (artículo 8). 
ser tendencialmente totalitario, pese a la letra contraria de varios preceptos constitucionales.

Además de las razones puramente normativas que permiten hablar de un diseño constitucional autoritario y tendencialmente totalitario, se agregan aquellas que también enfocan la Constitución como una realidad psicosocial que responde a la historia, valores y cultura de la sociedad que la genera y desarrolla.

En el caso venezolano, no es nada desdeñable el poderío económico del Estado, que cuenta, por mandato constitucional, con la titularidad patrimonial de la principal fuente de ingresos de la sociedad, el petróleo, monopolio económico básico en la organización social venezolana moderna que unido, como es propio, al monopolio de la fuerza armada y policial, constituye un haz de elementos que anudan en un solo centro la fuerza económica (petróleo), la fuerza física (armas), la fuerza normativa (poder normativo habilitante), a la par de un debilitamiento de la descentralización (composición y competencias del Consejo Federal de Gobierno).

De este modo, la "construcción" de una sociedad justa, lo autoriza para convertirse en señor absoluto de los criterios de justicia y del modelo de esa sociedad y del poder, en todas sus caras. Por eso, no es apenas un Estado de Bienestar.

Contra esta conclusión, cabe argumentar que la CV-99 reconoce y garantiza derechos fundamentales incompatibles con un Estado totalitario; sin embargo, esta afirmación peca de ingenua ante la ordenación sistemática de su cuerpo normativo que privilegia determinados actos de poder frente a los derechos individuales, y la no menos importante fuerza de dinámica realización de los conceptos enhiestos en el mismo y que, a la postre, define la solución de los conflictos.

Es verdad que ningún documento constitucional pone punto final y definitivo a los conflictos axiológicos y normativos que presentan su texto y su despliegue histórico, sino que más bien se nutre de ellos, de allí la relevancia de la interpretación constitucional y sus principios para su solución racional y la obtención de resultados "correctos". Por ello, podría decirse que la hipótesis sostenida no es más que el resultado de una interpretación posible, frente a la cual hay otras también plausibles. De allí que 
valga detenerse algunos instantes en torno a la interpretación en el orden constitucional.

Según Hesse, en materia constitucional, es muy importante la interpretación dado el carácter "abierto y amplio" de sus normas, ${ }^{55}$ y que si bien las interpretaciones del tribunal o de la sala constitucional son vinculantes, no por ello tales órganos están por encima de la Constitución. Luego, el cumplimiento correcto de su cometido, alcanzar el "resultado correcto", ${ }^{6}$ exige "un procedimiento racional y controlable", que fundamente dicho logro "de modo igualmente racional controlable, creando de este modo, certeza y previsibilidad jurídica, y no, acaso, el de la simple decisión por la decisión". ${ }^{57}$

La "corrección" de un resultado de interpretación es fruto del respeto y desarrollo de los derechos humanos; sin embargo, cuando la armadura constitucional contiene elementos con vocación decisoria de fuerza material (económica, bélica, policial e institucional), la "corrección" pudiera ser entendida en una clave positivista rígida, a espaldas de las corrientes de pensamiento prevalecientes en pro de esos derechos y de la autonomía de la voluntad. En pocas palabras, suscitar interpretaciones contrarias a los derechos humanos. Y no solo eso, sino que puede favorecer, como en la CV-99, que la solución de los conflictos transite a dominios distintos de lo jurídico y judicial, donde disminuya la capacidad efectiva del Derecho en la defensa y resguardo de derechos fundamentales.

Por ello, no es fruto de la casualidad ni solo de la desviación de poder, que el proceso político totalitario que ha padecido la sociedad venezolana desde 1999 se ampare bajo la CV-99, sin que esto implique negar que muchos de los actos de gobierno y de legislación que han marcado el desarrollo del socialismo hayan contado con violaciones constitucionales de naturaleza procedimental, primordialmente.

Ejemplo de lo dicho es la tesis de Jorge Giordani, uno de los artífices de la imposición del modelo socialista como Ministro de Planificación, según

55 Hesse (2011) p. 58.

56 Analizar la diferencia entre "correcto" $y$ "verdadero" tiene una importancia que escapa a los límites de este artículo; sin embargo, no sobra indicarlo.

57 Hesse (2011) p. 58. 
la cual aunque la CV-99 no registre el vocablo "socialista" o "socialismo", sin embargo, sí se adelantó en esa dirección "al devenir del proceso de construcción de una nueva sociedad que tenga el signo del socialismo". ${ }^{58}$ Sostiene que es un modelo socialista basado en el fortalecimiento del Estado rentista, es decir, apalancado en la renta petrolera, monopolio del Estado, ${ }^{59}$ por lo que resulta evidente que el marco constitucional es perfectamente compatible con el socialismo y tendencialmente totalitario, además de las claves antes expuestas.

Por tanto, la condición y tendencia de la CV-99, en los términos que se han señalado, no resulta de un proceso interpretativo caprichoso, sino que responde a la racionalidad del texto y a la realidad económica, con respaldo constitucional, además de la herencia de historia caudillista y militarista, incompatible con la democracia liberal, cuyo alcance pudiera examinarse en estudios histórico-culturales.

Adicionalmente, hay que considerar que la CV-99 emplea como uno de sus más sagaces ardides, el reconocimiento, entre otros, de derechos y garantías de naturaleza económica, que podrían ser considerados como bienes jurídico-penales, razón por la cual se analizan a continuación.

\section{NORMAS CONSTITUCIONALES ECONÓMICAS PENALMENTE RELEVANTES}

\section{Introducción}

El constituyente, cuando desarrolla los derechos económicos (Capítulo VII del Título III, correspondiente a los derechos humanos y garantías, y los deberes), inserta derechos, prohibiciones, deberes, garantías y delitos (mandatos). ${ }^{60}$

58 GIORDANI (2009) p.35.

59 GIORDANI (2009) p. 78.

60 De modo similar, en la Disposición Transitoria Quinta sobre el régimen fiscal y tributario en la cual se prevé la eliminación de la prescripción legal para los delitos tributarios graves a tipificarse en el Código Orgánico Tributario; ampliación de las penas "contra asesores o asesoras, bufetes de abogados o de abogadas, auditores externos o auditoras externas u otros u otras 
Estos mandatos poseen un contenido semántico jurídico-penal denominativos de los injustos -especulación, acaparamiento, usura, cartelización- ${ }^{61}$ más difundidos en la legislación, están sometidos a una ponderación menos reglada que otras disposiciones más generales. A continuación, una breve sinopsis.

\title{
2. Prohibiciones, facultades y mandatos de criminalización
}

\author{
Están contenidos básicamente en los artículos $113^{62}$ (prohibiciones y facul- \\ tades), $114^{63}$ (mandatos de criminalización) y $117 .{ }^{64}$
}

profesionales que actúen en complicidad para cometer delitos tributarios, incluyendo períodos de inhabilitación en el ejercicio de la profesión"; ampliación de las penas y severidad de las sanciones contra delitos de evasión fiscal con aumento de los períodos de prescripción y revisión de atenuantes y agravantes para que sean "más estrictas". El artículo 317 constitucional prevé la tipificación, potestativa, de la evasión fiscal.

61 Lo anterior no quiere decir que estos injustos gocen de una pacífica y uniforme significación, ni tampoco que sean igualmente considerados siempre como materia de punición, pero no puede negarse que gozan de algún "abolengo" jurídico penal, lo que facilita la determinación de su significado, según la doctrina, jurisprudencia o derecho comparado. Otra cosa es que se comparta su penalización. No es insensato suponer que, en razón de la ideología de la CV-99, los asambleístas actuaron animados por un espíritu adverso a la libertad económica, propenso alábaros terminológicos para flagelar, con razón o sin ella, los desvaríos del ejercicio de la libertad económica, que como toda facultad humana no está exenta de abusos y errores, incluso atropellos, sino también atentar contra la misma libertad.

62 "En todos los casos antes indicados (monopolios, abuso de posición de dominio, demanda concentrada) el Estado adoptará las medidas que fueren necesarias para evitar los efectos nocivos y restrictivos del monopolio, del abuso de posición de dominio y de las demandas concentradas, teniendo como finalidad la protección del público consumidor, de los productores y productoras, y el aseguramiento de condiciones efectivas de competencia en la economía." (el destacado es propio). El guiño constitucional a la competencia en mi opinión no desmejora la tesis que he venido sustentando, pues se trata de una norma subordinada a un sistema con sentido y naturaleza interventora. Es tanto como proclamar una suerte de "competencia planificada".

63 "El ilícito económico, la especulación, el acaparamiento, la usura, la cartelización y otros delitos conexos, serán penados severamente".

64 "Todas las personas tendrán derecho a disponer de bienes y servicios de calidad, así como una información adecuada y no engañosa sobre el contenido y características de los productos y servicios que consumen; a la libertad de elección y a un trato equitativo y digno. La ley establecerá los mecanismos necesarios para garantizar esos derechos, las normas de control de calidad y cantidad de bienes y servicios, los procedimientos de defensa del público consumidor, el resarcimiento de los daños ocasionados y las sanciones correspondientes por la violación de esos derechos". 
Los mandatos de criminalización del artículo 114 pudieran leerse prima facie como contra cara de los derechos del consumidor como bien jurídico, cuyo contenido aporta el artículo 117, a su vez asociado al Decreto con rango, valor y fuerza de Ley Orgánica de Precios Justos, amalgamada con la penalización de la infracción de deberes ante la intervención del Estado en la actividad económica. ${ }^{65}$

Entre esos mandatos está el delito de especulación, que, como ha reseñado Fernández, ${ }^{66}$ fue previsto por el Código Penal de la Unión Soviética de 1922 y fue uno de los medios de los que se valió Stalin para perseguir a sus enemigos políticos.

Adicionalmente, el texto constitucional reconoce un conjunto de derechos económicos - principal argumento de los defensores de la tesis de la recepción constitucional de la economía de mercado-, junto a otras normas que podrían vincularse a la determinación del bien a proteger.

\section{Derechos, ${ }^{67}$ condiciones, garantías y deberes económicos}

Según el artículo 112 de la CV-99, el derecho a la libertad económica sufre limitaciones constitucionales y legales por razones de desarrollo humano, seguridad, sanidad, protección del ambiente y otras de interés social. Estas limitaciones, como antes se vio, se pueden denominar condiciones, ${ }^{68} \mathrm{y}$ su alcance lo determina el Estado según la "creación y justa distribución de la riqueza", que, mediante su planificación, responde las interrogantes sobre cuándo y cómo la riqueza se crea, y a quién y bajo cuáles criterios se distribuye de manera "justa".

Por lo tanto, el contenido y extensión del derecho a la libertad económica -de trabajo, de empresa, de comercio, de industria- están profundamente

65 Su incorporación al texto constitucional también posiblemente proviene del propósito de condenar el uso de la razón en la convivencia, si se la emplea en forma opresiva e intolerante. El problema no está en la razón o en la voluntad en sí mismas consideradas, sino en el divorcio de ambas facultades con su ejercicio éticamente correcto.

66 Fernández (2018) p. 56.

67 "Económicos" en cuanto el ámbito de actividad de la libertad.

68 Se distinguen de las facultades específicas del Estado que también pueden menoscabar el ejercicio de la libertad económica. La diferencia consiste en su mayor especificidad. 
intervenidos por los criterios valorativos y políticos del poder político, lo que es distinto a las necesarias reglas a observar en el mercado, y garantizar la competencia, como reconocía incluso Adam Smith, para que haya una "justicia competitiva" que no niega la ley del mercado -oferta y demanda-, sino que la preserva bajo un signo liberal: "el Estado pone las reglas del juego, y quien actúa debe hacerlo en el respeto a las reglas". ${ }^{69}$

La dificultad está en si son reglas operativas o sustantivas. La fijación de precios, por ejemplo, es una regla sustantiva, pues incide precisamente en el factor que solo la competencia permite determinar, ya que corresponde a un ámbito de conocimiento que no posee el Estado, por lo que es erróneo sostener que la fijación de precios en un tope máximo es una regla propia de un mercado libre porque permite la competencia dentro de un rango. ${ }^{70}$

Cuando el Estado interviene y define mediante la planificación -conjunto de decisiones y valores que asume el mismo poder-, se convierte en instancia suprema de ordenación y concepción de la actividad económica, que deja de ser libre, como ab initio se prometió, para ser planificada, racionalizada y regulada, ${ }^{71}$ o sea, controlada. No hay tal cosa que sea una libertad planificada por otro.

69 Santosuosso (2016) p. 46.

70 Según Santosuosso (2016) p. 40, la fijación de precios máximos no colide con el mercado libre, pues la misma es una regla y no una actuación del Estado, que solo ocurrirá cuando los agentes económicos violen esa regla: "Esta es la esencia del liberalismo: el mercado no es jungla, sino que se debe mover en el respeto de las leyes que establece el Estado". Agrega Santosuosso (2016) p. 5o, que al Estado no le corresponde fijar los precios mediante la planificación central, porque no puede calcular la estructura de los precios, por carecer de un algoritmo para calcular el conocimiento tácito de los consumidores, como el mismo Santosuosso reconoce tímidamente cuando afirma "que los hechos terminaron demostrando que von Hayes tenía razón". Entonces, mal puede fijar precios máximos, pues no posee el "conocimiento tácito" del consumidor.

71 GIORDANI (2009) p.98, en palabras que no dejan lugar a dudas de la eminente relación entre socialismo y planificación, dice: "La planificación en su sentido pleno del término es un rasgo esencial del control metabólico social socialista, tanto en su impacto inmediato como en el lejano tiempo histórico futuro... (omissis)... La antagonística relación entre los Estados nacionales y la presencia transnacional de las corporaciones productivas a nivel de la entera esfera terrestre requiere implementar un tipo de planificación que parta de los seres humanos y que los involucre en las decisiones sustantivas que atañen a la satisfacción de sus necesidades de manera de sobreponer la actual dinámica dominante del valor de cambio en el sistema productivo en particular, y en la sociedad en general. El proceso de acumulación capitalista debe ser dejado de lado por una distribución de recursos que empleen adecuadamente el tiempo de trabajo en función de esas necesidades vitales". 
Por otra parte, aunque el sistema jurídico intervencionista diga reconocer derechos económicos individuales, como la libre competencia y la iniciativa privada, su coexistencia con la justicia social no es dialéctica, sino antagónica según los mismos términos de la Constitución, por cuanto se someten al fin de la "justa distribución de la riqueza", procurada mediante una "planificación estratégica, democrática, participativa y de consulta abierta". El antagonismo existe por lo siguiente.

La libertad no es compatible con una planificación heterónoma como su ámbito de realización, aunque puede ser su límite, en casos de Estados intervencionistas y no iliberales en el terreno ético-político de los derechos humanos.

A su vez, la definición de fines ${ }^{72}$ e instrumentos, por su condición racionalizada, exige cohesión y perdurabilidad según constantes, lo que no es compatible con la apertura permanente de la condición supuestamente democrática de la planificación prevista en la CV-99. Mas, no se trata exclusivamente de un tema teórico, sino también de la práctica del conjunto normativo, si por ella se entiende su operatividad y la significación derivada de su dinámica social, o sea, su "biografía".

El diseño socioeconómico de la CV-99 es inequívoca expresión del dirigismo económico -autoritarismo en su dimensión política-, que pretende conformar la sociedad y sus instituciones por un ente pretendidamente superior en conocimientos, habilidades y conciencia moral a la de los individuos, rebajados a instrumentos de un plan diseñado y ejecutado por el Estado, que, como abstracción, se reduce a la postre a un determinado grupo de "iluminados" individuos con poder, cuando no a un solo sujeto que domina sus grupos de apoyo y seguimiento.

El plan estatal resuelve el antagonismo entre la libertad económica y el intervencionismo a favor del último. En consecuencia, siendo la contraposición una tensión extrema generadora de inestabilidad que impide el desarrollo de las variables hacia una síntesis superior y, por el contrario, se resuelve en el predominio de una sobre la otra, resulta que la CV-99 está afectada

72 Los fines para ser objetivos operativos no se pueden establecer con la participación pública de todos, y en lo económico el Estado, centro del poder, es el que fija los objetivos que orientan su estrategia 
por un máximo desequilibrio conducente a un orden tendencialmente totalitario, aunque revestido de formas democráticas que paulatinamente van cediendo al avance de las patologías totalitarias que se diseminan hasta lograr el pleno dominio del sistema, en sus conceptos y en su práctica.

En conclusión, las condiciones del ejercicio de los derechos económicos autorizan al Estado para una "intervención positiva" al definir su ámbito y límites, desde fórmulas indeterminadas (lo que establezca la Ley), hasta otras que penden de otras más generales ("fines de utilidad pública o de interés general", por ejemplo, en materia de propiedad). ${ }^{73}$

Esbozado lo relativo a los derechos y sus condiciones, faltan las prohibiciones y los deberes, a los que me refiero a continuación.

Las prohibiciones no establecen positivamente el contenido de derechos, sino que fijan límites negativos que, incluso, en ocasiones, pueden ser considerados como garantías ante el posible abuso de sus titulares, como sucede con la interdicción de la confiscación, con la diferencia de que este mandato se dirige al Estado y no al particular. Por tanto, su peso es menor que el de las condiciones sobre la extensión y ámbito de los derechos económicos.

Los deberes son estatales o públicos-privados. Los primeros atienden a funciones estatales y son correlativos al respeto de los derechos individuales, según la perspectiva demoliberal. ${ }^{74}$ Los segundos vinculan a los ciudadanos al poder estatal, como los tributarios, por ejemplo.

Es posible diferenciar, desde la perspectiva del obligante, entre deberes estatales fuertes o poderes, y deberes estatales débiles o facultades, que

73 La expropiación solo procede por causa de utilidad pública o social, mediante sentencia firme y pago oportuno de justa indemnización (Artículo 115).

74 Demoliberal o liberal son empleadas como expresiones fundamentalmente sinónimas, aunque es claro que en la primera se vincula el principio democrático del ejercicio mayoritario del poder con el principio liberal de la libertad, lo que conduce al respeto a la minoría y, por tanto, la limitación del poder. El respeto a la minoría es un valor ético-político que se despliega en la tolerancia que se nutre también del sentimiento de la solidaridad, o mejor aún, de la colaboración como la actividad que la manifiesta y gracias a la cual la igualdad ante la ley, instancia normativa, y la igualdad como sentimiento de solidaridad, instancia afectiva, se conjugan en los valores de la democracia y el liberalismo, como categorías de pensamiento y acción que definen la civilidad moderna. 
actúan como condiciones de segundo grado del ejercicio de los derechos económicos. Dependen del poder del Estado y tienen un carácter más específico. Puede decirse que, en algunos supuestos, son garantías reforzadas de derechos, y se distribuyen entre los artículos 113, encabezado in fine y $116^{75}$ constitucionales.

Las garantías son genéricas, previstas en el artículo 112 -confundidas con limitaciones-, o específicas, como las enunciadas en la parte in fine del encabezado del artículo 113, donde se confunden con los deberes estatales débiles o facultades. La diferencia estriba en el punto de enfoque.

Revisado el universo normativo básico de la CV-99 relevante para descifrar el bien jurídico penal económico constitucional, es necesario abordar esta categoría con algo más de detenimiento, pues como acertadamente dice Regis Prado, en un Estado de Derecho la tutela penal no se disocia del bien jurídico, que deviene en legítimo, cuando resulte socialmente necesario. ${ }^{76}$ Sin embargo, la necesidad social no es un criterio desprovisto de valores, por lo que es necesario explorarlos.

\section{VII.- EL BIEN JURÍDICO ECONÓMICO CONSTITUCIONALMENTE DEFENDIDO Y RESGUARDADO}

\section{Derechos individuales}

Exceptuando la enunciación de los derechos económicos, la CV-99 no abundan en disposiciones expresas que consagren bienes jurídicos económicos, salvo, quizá, los derechos del consumidor, parcialmente desarrollada $^{77}$ en el decreto ley sobre precios justos, y la seguridad alimentaria, materia de la ley sobre la seguridad y soberanía alimentaria.

75 Excepcionalmente, se pueden confiscar, por sentencia firme, bienes de personas naturales o jurídicas, nacionales o no, responsables de delitos contra el patrimonio público o de quienes se hayan enriquecido ilícitamente al amparo del Poder Público, así como bienes provenientes de las actividades comerciales, financieras o cualesquiera otras vinculadas al tráfico ilícito de sustancias psicotrópicas y estupefacientes.

76 Regis Prado (2010) p.65.

77 Parcialmente porque privilegia los mandatos de obediencia al Estado. 
La seguridad alimentaria corresponde a las políticas que competen al Poder Nacional (Artículo 156, numeral 23), y, es, además, una garantía prestacional del Estado, según el artículo 305 eluden: El Estado promoverá la agricultura sustentable como base estratégica del desarrollo rural a fin de garantizar la seguridad alimentaria de la población (destacado propio). Así, la promoción de la agricultura sustentable es el medio del objetivo final: seguridad alimentaria.

\section{Derechos de actividad organizacional}

Otras normas recaen sobre concretas áreas de la actividad económica. Entre ellas, la bancaria, cuya regulación legal fue antes indicada, y la aseguradora, que no cuentan con expresas disposiciones constitucionales que acrediten su relevancia jurídica penal, salvo que su inclusión, en el elenco de las materias propias de la competencia del Poder Nacional, se considere en sí misma como signo de su importancia.

Algo similar sucede en el mercado de valores, a menos que la fórmula "mercado de bienes" incluya el mercado de valores en orden a la prohibición de abuso de posición de dominio del artículo 113.

La delincuencia organizada (internacional) no es una categoría constitucional de significación criminal directa; sin embargo, aparece en el artículo 271, entre los delitos por los cuales no puede ser negada la extradición de extranjeros.

\section{Deberes públicos-privados}

Los deberes públicos-privados, como el tributario, se pueden considerar contenido de bienes jurídicos. Fuera de este supuesto, resultan penalmente significativos en casos excepcionales de afectación a valores fundamentales para la convivencia social. Es cierto que esta premisa peca de imprecisión, y por eso obliga -he ahí las ventajas de las imprecisiones en el debate liberal- a un esfuerzo argumentativo que persuada de la necesidad de su defensa y regulación, en un proceso dialógico donde concurren la tradición legislativa, los procesos históricos y la cultura como avales de las decisiones legislativas y administrativas. 
En cuanto el bien jurídico en materia fiscal, hay que agregar que si no hay, ante el deber fiscal, un derecho individual en contrapartida, sí existe un reconocimiento de la importancia de la obtención de ingresos por parte del Estado para el acometimiento de sus funciones básicas de seguridad, ${ }^{78}$ defensa, salud y vías de comunicación, al menos en Venezuela. ${ }^{79}$ Estas funciones, por supuesto, están expuestas a variaciones históricas, culturales y sociales.

La revista al conjunto de la CV-99 con alcance jurídico penal relevante, no ha agotado la pregunta acerca de los bienes jurídicos que pueden ser constitutivos de injustos penales económicos, pues la plataforma constitucional no es por sí sola constitutiva de injustos penales, pues hay requisitos adicionales al contenido de las normas, como son el modo e intensidad del ataque, cuyos detalles escapan a este artículo.

Tema sustancial de los bienes jurídico-penales económicos es el de los derechos sociales o transpersonales, lo que amerita algunas palabras ${ }^{80}$, como materia de bienes jurídicos penales económicos.

78 El concepto de seguridad adquiere en la CV-99 una descomunal magnitud, propia de un Estado tendencialmente totalitario, artículo 326: "La seguridad de la Nación se fundamenta en la corresponsabilidad entre el Estado y la sociedad civil para dar cumplimiento a los principios de independencia, democracia, igualdad, paz, libertad, justicia, solidaridad, promoción y conservación ambiental y afirmación de los derechos humanos, así como en la satisfacción progresiva de las necesidades individuales y colectivas de los venezolanos y venezolanas, sobre las bases de un desarrollo sustentable y productivo de plena cobertura para la comunidad nacional. El principio de la corresponsabilidad se ejerce sobre los ámbitos económico, social, político, cultural, geográfico, ambiental y militar".

79 En materia de educación cabe decir que es una función básica del Estado hasta cierto nivel, pero siempre compartida. Si bien la salud también es compartida, no tiene el límite que hay en materia de educación. Es un tema sensible y discutible, para no decir opinable, sobre todo si se tiene en cuenta la importancia que tiene la educación, incluyendo la superior, para el avance de los pueblos, aunque es de resaltar que la sola educación no es garantía ni de cultura ni de desarrollo moral. La Segunda Guerra Mundial es un buen ejemplo de que el refinamiento cultural no impide por sí sola la bestialidad de las fuerzas agresivas y destructoras del ser humano. La ciencia, la tecnología, las instituciones liberales, la educación y en no menor medida la religión, junto a los valores morales y el desarrollo de la conciencia ética y estética conforman la cultura humanista que puede proteger a la humanidad de la barbarie. La civilización no ha logrado expulsar un errado misticismo mágico y las pasiones egoístas y destructoras que hicieron gala de su poderío durante el curso del maltrecho siglo XX, espléndido en tantas y otras distintas cosas.

80 Los derechos individuales, en principio, se recluyen en los delitos contra el patrimonio. 


\section{Derechos sociales y derechos socio-institucionales}

Entre sus características, destaca la universalidad, estrechamente asociada a su titularidad, y ésta, a su vez, a la legitimidad de la sanción penal por menoscabo de su ejercicio o disfrute, diferente de la que es propia de los derechos individuales, aun cuando la distinta titularidad de unos y otros $^{81}$ se entienda en dos sentidos. La primera alude a la colectividad como carácter definitorio de su condición; la segunda, como no exclusión de individuos.

La diferente titularidad no es simplemente un dato cuantitativo, sino que afecta sus posibilidades de desempeño, ejecución y efectividad, que puede ser visto como un accidente histórico, espacial o temporal, o como consecuencia de su abstracción. Estas dificultades han contribuido a la tesis de que los sociales no son derechos, sino aspiraciones, expectativas, promesas, buenas intenciones.

Las posibilidades de ejercicio material de los derechos no definen ni determinan per se la condición de derecho como tal, pues pueden ser accidentes históricos ajenos a su "sustancia normativa". ${ }^{82}$ Ahora, si considera que el Estado Social de Derecho es un estadio avanzado de la acción del Estado Liberal, donde los "derechos sociales" cuentan con la misma garantía de efectividad de los principios del liberalismo clásico, se demostraría una capacidad de adaptación y evolución infinitamente superior a la del pensamiento colectivista, así como su adaptabilidad a las condiciones materiales que garanticen el ejercicio efectivo de la libertad. Sería la concreción, al menos normativa, de esas posibilidades materiales.

Sin embargo, este punto de vista tampoco es unánime. En Venezuela, José Valentín González ha sostenido que no es posible la conciliación entre la

81 Los derechos individuales son universales en cuanto corresponden a todos los individuos sin exclusión. Los sociales son universales en otro sentido: corresponden al universo humano como totalidad unitaria. La primera universalidad se eleva sobre la unicidad, la segunda sobre la totalidad, en la cual la unicidad es una referencia posterior, no inmediata.

82 La definición de lo que sea "sustancia normativa" es una opción teórica con carga ideológica, ética y política, si por ideología se entiende un concepto más amplio que el limitado y desprestigiado a que lo sometió el discurso marxista, y se concibe como un conjunto de ideas y propuestas ordenadas que presiden un discurso que revela el sustrato teórico de la acción humana que suma la teoría (epistemología) a la praxis (eticidad) y es, además, definitorio de la pragmática (oportunidad, estrategia, utilidad). 
libertad y el "poder configurador del Estado Social", por lo que en modo alguno el Estado Social y Democrático de Derecho es un modelo insuperable, como tampoco lo fue la Unión Soviética cuando se decía que era "un régimen permanente". En pocas palabras, en su opinión, la lucha por la libertad sigue estando vigente ante el Estado Social. ${ }^{83}$

En cualquier caso, cuando unas expectativas son denominadas "derechos", adquieren una fuerza jurídica simbólica ${ }^{84}$ importante que gravita sobre la actividad del Estado y el imaginario social, aunque también pueden su estructura considerada como"especie" de derechos.

Su estructura no revela la misma relación de posición normativa del individuo ante el Estado, cuando pretende de éste una prestación. Se da una interacción opaca, en la cual la realización del derecho depende de condiciones materiales y operativas que se superponen a su efectividad; mientras que en el caso de los derechos individuales dicha superposición, de ocurrir, se valora como vulneración y no límite de ejecución. Sin embargo, hay casos en los cuales se han ejercido acciones de tutela constitucional en representación de intereses colectivos o difusos contra órganos del Estado, que han culminado con decisiones judiciales efectivas. Si ello demuestra una discutible identidad entre derechos sociales y derechos de sujetos con intereses colectivos y difusos -concepto procesal y no sustantivo-, entonces estos últimos reproducen la estructura de los individuales y la prestación se convierte en obligación. Por tanto, el derecho social sería la extensión de derechos individuales, pero condicionado a un relativismo histórico, cultural e institucional.

En cualquier caso, la emersión de los derechos sociales, por su debilidad conceptual e institucional, en provincias penales o es puramente simbólica, o mutan en instrumentos de persecución política, sobre todo si de Estados autoritarios, o tendencialmente totalitarios, se trata.

Dentro de los derechos sociales ubicamos los socio-institucionales, relacionados con la creación, protección y defensa de las instituciones ${ }^{85}$ que

83 GonzÁlez (2012) p. 19.

84 Para los defensores de la tesis de los derechos sociales como auténticos derechos, esa fuerza no es meramente simbólica. Este punto ameritaría una disertación que excede los límites y objetivos del presente artículo.

85 En sentido amplio, las instituciones son unidades de realización conjunta de actividades con 
fundamentan la organización jurídica de la sociedad y del Estado. En este caso, no hay aporías a la protección penal de la administración pública, de la administración de justicia, de la fe pública o de la propia independencia y soberanía del Estado, entre otras provincias penales, siempre y cuando se cumplan los cánones de legalidad, proporcionalidad y otros propios del orden jurídico penal moderno, o sea, demoliberal. Son instituciones básicas para el desarrollo y conservación de la organización jurídica de la sociedad y el desarrollo de la autonomía de la voluntad, según premisas liberales, de allí la denominación de socio-institucionales, y cuya tutela penal en Estados autoritarios o iliberales no tiene un sentido de defensa del ciudadano en la realización de su autonomía, sino que busca el fortalecimiento punitivo de las órdenes estatales, al margen -e incluso en contra- de los valores individuales.

Las instituciones se asocian a la realización del proyecto de vida de los individuos y al reconocimiento de sus derechos, según la evolución ética, institucional y política de la sociedad, contexto de su titularidad. La vinculación con la realidad social las condiciona transitivamente como espacios propicios a ese desarrollo, y cuando su función es afectada, es posible, racional y legítima la intervención del Derecho Penal, sin dar lugar a una "inflación" o "expansión" del Derecho Penal en términos negativos, sino que se tratará de un desarrollo y perfeccionamiento del Derecho Penal, que es otra cosa. Más allá, el Derecho Penal traspasa los límites que le son propios como marco de reducción del poder estatal.

Esta posición pudiera ser calificada de individualista y de espaldas a la inflación del Derecho Penal contemporáneo, pero la existencia de un hecho no es prueba de su validez o legitimidad, a lo sumo es prueba de su existencia, que puede ser aprobada o no, justa o no, valiosa o no.

En conclusión, los derechos sociales transmutados en instituciones sí son materia legítima de protección penal. En otro caso, pueden ser núcleo de bienes jurídicos si se vinculan solamente a derechos individuales. En ambos supuestos, el modo y medio de ataque ha de ser particularmente reprochable, y no haya otro medio de defensa y resguardo.

elevado poder simbólico e identificatorio de sus miembros como partícipes de esa unidad social con abolengo histórico, necesarias para la realización del proyecto existencial de los individuos. 


\section{La norma como objeto de protección penal}

La tesis del funcionalismo radical ${ }^{86}$ sobre la finalidad protectora de la norma como justificante del Derecho Penal, es sumamente peligrosa porque el Estado puede extralimitarse en la creación de normas. Así, la débil fuerza limitante del poder que se le reprocha al bien jurídico, no se supera porque el referente cambie de asiento.

No es cierto que la normatividad sea límite necesario y suficiente para el poder, especialmente el político-estatal, que no es solo una realidad normativa, pues dispone de otros recursos y fuentes de dominio, como es el caso venezolano. Por ello, el seto del Derecho es precario e insuficiente, aunque necesario. Por tanto, la erección de la norma no logra mayor seguridad que el bien jurídico, como justificante de la intervención punitiva, sino todo lo contrario.

Ciertamente que el Derecho Penal cumple una función de identidad ético política, en el plano preceptivo, como otra de reafirmación de esa identidad en el plano punitivo, pero ambas no son idénticas, y pueden llegar a complementarse en la medida en que normativicen armónicamente principios y valores ateniendo a unidades de sentido finales, los bienes jurídicos. Así, en una concepción liberal, la conciencia ética política es el punto de partida, las normas el tránsito, y los bienes los puertos de llegada. Por ello, el funcionalismo radical tiene parte de verdad, pero yerra cuando toma la parte como totalidad.

\section{La CV-99 como fuente legítima de bienes jurídico-penales económicos}

En primer lugar, hay que tener presente que el bien jurídico es, por definición y, primeramente, algo bueno -persona, cosa, institución-, es decir, valioso, merecedor de aprobación en sí mismo o en razón de fines dignos de ser alcanzados, condición valiosa que es otorgada por la estimación socio-cultural o por el reconocimiento constitucional.

86 El funcionalismo radical da importancia exponencial a conceptos impersonales como la "función", el "rol", el "sistema", que pavimentan la vía hacia nuevas versiones del totalitarismo, exponiendo a grave peligro la integridad de los valores y principios del derecho penal liberal. 
Por otra parte, sin estudiar profundamente el contenido del bien jurídico, asunto que escapa a la naturaleza misma de este trabajo, hay que afirmar que no puede ser bueno lo que niegue la condición libertaria del individuo, pues el ser humano sin libertad está privado de la condición mínima de su rango ético y, por tanto, de su humanidad. Por eso, en la perspectiva demoliberal no es suficiente establecer la condición jurídica de la actividad económica.

En el caso de la CV-99, a su reconocimiento, que se sintetiza alrededor de las zonas de control y de dominio supra referidas, se añade, primero, la necesidad de determinar su cualidad valiosa en tanto su correspondencia con los valores de libertad y dignidad, y, en segundo lugar,especificar si la respuesta penal a su afectación es cónsona en grado, medida, definición fáctica y punibilidad con un Derecho Penal limitador del ius puniendi, de lo que depende su legitimidad que, en definitiva, se sostiene por la comparación entre la intervención penal y otros medios potencialmente idóneos para alcanzar el mismo fin socio-normativo. La legitimidad también proviene de la proporcional intensidad en la intervención de los derechos del culpable.

Por último, además de los anteriores criterios, hay que analizar el grado de tensión, en el mismo discurso constitucional, entre los valores y principios propios de la libertad económica y el conjunto normativo restante.

Por tanto, una Constitución Económica que se levante sobre la negación de la libertad económica, o en la cual la tensión de sus elementos se resuelve a favor del predominio del poder sobre la libertad, no puede abrigar ningún bien jurídico penal económico, ni ser punto de referencia del mismo.

Otro asunto es el conjunto de intereses del Estado sobre sus políticas y directrices, pero ello no los convierte en bienes jurídicos, y, por tanto, no justifican la restricción de derechos fundamentales, y cuando ello ocurre, como en el caso venezolano, entonces no es por daño o puesta en peligro de bienes jurídicos, sino por la desobediencia al mandato estatal, característica propia de los Estados autoritarios o tendencialmente totalitarios. 


\section{CONCLUSIONES}

El modelo socioeconómico de la CV-99 es propio del Estado de Bienestary tendencialmente totalitario, por tanto, ajeno a la economía social de mercado, y si bien no es socialista expressis verbis, sus normas no excluyen la economía socialista.

La CV-99 es un texto inestable por su antítesis entre sus presupuestos, lo que no es fruto del azar, sino que es consustancial a su discurso.

Esta antítesis se resuelve a favor del predominio de uno de los elementos del sistema discursivo sobre otro. Es decir, el predominio del intervencionismo sobre los elementos democráticos y liberales dispersos en varias normas coloreadas como derechos humanos.

El dirigismo económico no engendra bienes jurídicos porque el contenido de los objetos protegidos, no puede estar al margen de la mínima condición ética de la responsabilidad humana, que no es otro que el ejercicio de su libertad que en el eje de la existencia social se denomina autonomía de la voluntad.

Las células liberales y democráticas en la CV-99 impiden hablar de totalitarismo, desde el punto de vista normativo, otra cosa es la dimensión de la real politik. La diferencia quizás esté solo en el tiempo.

\section{BIBLIOGRAFÍA CITADA}

Álvarez, Tulio (2012): Instituciones Políticas y Derecho Constitucional (5 ${ }^{\mathrm{a}}$ edición ampliada y actualizada, Caracas, Universidad Católica Andrés Bello).

Arteaga, Alberto (2012): Derecho Penal Venezolano (12 ${ }^{\text {a }}$ edición actualizada, Caracas, Álvaro Nora, Librería Jurídica).

Balcarce, Fabián (2014): Dogmática Penal y Principios Constitucionales (Montevideo, B de $f$ ). 
Brewer, Allan (2008): Historia Constitucional de Venezuela (Caracas, Editorial Alfa).

Fernández, Fernando (2018): El Estado Dual o anómico: efectos corrumpentes. Un caso, una lección: la justicia penal en Venezuela bajo el Estado dual y el Derecho Penal del enemigo (Editorial Académica Española).

Fernández Carrasquilla, Juan (2012): Derecho Penal. Parte General. Teoría del delito y de la pena. T. I (Medellín, Grupo Editorial Ibáñez).

García-Pelayo, Manuel (1991): Consideraciones sobre las cláusulas económicas en la Constitución. T. III (Madrid, Centro de Estudios Constitucionales).

GiORDANI, Jorge (2009): La transición venezolana al socialismo (Caracas, Vadell Hermanos Editores).

Gómez, Jesús (2008): La Teoría del Delito desde la perspectiva de la Constitución Venezolana (Barquisimeto, Judea Fondo Editorial).

Gros, Héctor (2005): Ética, bioética y Derecho (Bogotá, Editorial Temis).

GonzÁLEZ, José (2012): "Las tendencias totalitarias del Estado Social y Democrático de Derecho", en Democracia Participativa. T. VIII (Caracas, Acceso a la Justicia.org. Fundación Estudios de Derecho Administrativo. Universidad Metropolitana).

Hesse, Konrad (2011): Escritos de Derecho Constitucional (Trad. Pedro Cruz Villalón y Miguel Azpitarte Sánchez, Madrid, Fundación Coloquio Jurídico Europeo. Centro de Estudios Políticos y Constitucionales).

MÁrquez, Carmen (2014): Interpretación evolutiva de la Constitución y teorías de interpretación constitucional (Caracas, Konrad Adenauer Stiftung y Universidad Católica Andrés Bello).

Mila, Frank (2014): Manualde Derecho Penal. Parte General (Caracas, Livrosca).

Modolell, Juan (2015): Derecho Penal. Teoría del Delito (Caracas, Universidad Católica Andrés Bello). 
Moratalla, Agustín (2014): Democracia y caridad. Horizontes éticos para la donación y la responsabilidad (Basauri, Editorial Sal Terrae).

PeÑA, José (2008): Lecciones de Derecho Constitucional General. T. I Los derechos civiles. T.I (Caracas, Universidad Central de Venezuela. Facultad de Ciencias Jurídicas y Políticas).

(2014): Lecciones de Derecho Constitucional Venezolano. Los derechos políticos, sociales, culturales y educativos, económicos, de los pueblos indígenas y ambientales. T.II (Caracas, Paredes Editores).

Ramírez, Santiago (1999): "Teoría general de sistemas de Ludwig von Bertalanffy", en VV.AA. Ramírez, Santiago (Coord.), Perspectivas en las teorías de sistemas (México D.F., Siglo Veintiuno Editores) pp. 11-24.

Regis Prado, Luiz (2010): Bien jurídico-penaly Constitución (Trad. Luis Enrique Álvarez Aranda, Lima, Ara Editores).

Roxin, Claus (2014): La teoría del delito en la discusión actual (Trad. Manuel A. Abanto Vásquez, $4{ }^{\mathrm{a}}$ edición, Lima, Editora Jurídica Grijley).

SAntosuosso, Giulio (2016): Socialismo en un paradigma liberal ( 3 a edición, Caracas, Editorial Galac).

Sotelo, Ignacio (2010): El Estado social. Antecedentes, origen, desarrollo y declive (Madrid, Editorial Trotta).

VAN PARIJS, Philippe (1992): ¿Qué es una sociedad justa? Introducción a la filosofía política (Buenos Aires, Ediciones Nueva Visión).

Voltes, Pedro (1978): La teoría general de sistemas (Barcelona, Editorial Hispano Europa). 


\section{NORMAS JURÍDICAS CITADAS}

Constitución de la República de Venezuela, del 23 de enero de 1961.

Constitución de la República Bolivariana de Venezuela, del 24 de marzo de 2000.

Constitución del Reino de España, del 29 de diciembre de 1978.

Decreto con Rango, Valor y Fuerza de Ley Orgánica de Precios Justos, del 19 de noviembre de 2014 .

Decreto con Rango, Valory Fuerza de Ley de Instituciones del Sector Bancario, del 8 de diciembre de 2014.

Ley Orgánica de Ciencia, Tecnología e Innovación, del 26 de septiembre de 2001. 